\title{
MISTURADORES INTENSIVOS NA PREPARAÇÃO DE MINÉRIOS FINOS DE BAIXO TEOR DE FERRO NA SINTERIZAÇÃO*
}

Eduardo Cabral ${ }^{1}$

César Fernando Andina Eijo²

\section{Resumo}

A introdução da tecnologia intensiva de mistura nas plantas de sinterização de minério de ferro tem sido vital nos últimos 20 anos, dado o fato do progressivo afinamento do minério e a necessidade de manter ou até diminuir os custos operacionais das sinterizações. As características intrínsecas da mistura intensiva facilitam a incorporação de finos cada vez mais presentes nas formulações promovendo sua aglomeração de forma eficiente, sem perda de produtividade e com economia de coque, água e energia por tonelada produzida.

Palavras-chave: Sinterização; Finos; Mistura intensiva; Produtividade.

\section{PROCESSING IRON ORE FINES WITH INTENSIVE MIXERS IN SINTER PLANTS}

\begin{abstract}
The introduction of intensive mixing technology in iron ore sintering plants have been vital in the last 20 years, given the fact that the progressive thinning of the ore and the need to maintain or decrease the operating costs of the plant. The intrinsic characteristics of the intensive mixing makes easy the incorporation of fines, present in the ore nowadays, promoting the efficiently agglomeration without loss of productivity and economy of coke, water and energy per ton produced.
\end{abstract}

Keywords: Sintering; Fines; Intensive mixing; Productivity.

1 Engenheiro de Materiais, Gerente de Vendas, Comercial, Eirich Industrial Ltda., Jandira, SP, Brasil.

2 Lic. em Comercialização e Administração de Empresas, Universidade de Palermo, MBA Negócios FGV, Vendedor, Comercial, Eirich Industrial Ltda., Jandira, SP, Brasil. 


\section{INTRODUÇÃO}

\section{1 - Cenário}

$\mathrm{Na}$ indústria de processamento de ferro estaremos enfrentando uma tendência mundial em que a proporção de finos ou ultrafinos estará continuamente aumentando, seja ela pelo afinamento do próprio sínter-feed ou pela necessidade de introdução de pellet-feed ou concentrado na sua formulação para aumentar o teor de ferro.

É uma preocupação das sinterizações ao redor do mundo buscar e encontrar soluções economicamente viáveis para manter a eficiência das instalações, tanto para plantas existentes quanto para novos projetos.

O objetivo desse trabalho é apresentar uma solução, por meio da utilização de misturadores intensivos verticais, explicando como ele pode melhor aglomerar os finos, a fim de não perder permeabilidade no leito do sínter.

\section{2 - Mistura Intensiva}

O conceito do misturador intensivo vertical foi desenvolvido em meados dos anos 70 para atender melhor os requerimentos do mercado industrial, que demandava uma capacidade de mistura mais eficiente e homogênea, em comparação com as tecnologias existentes. Surgiu nessa época toda uma geração de novos produtos que precisavam entrega adicional de energia para obter-se uma maior interação entre os agregados que compunham a formulação, começando pela indústria do concreto.

Esse conceito foi expandido para outros setores industriais, tal qual cerâmico, fundição, vidro, químico, baterias, pelotização e mais recentemente na sinterização.

Basicamente, mistura intensiva refere-se a quanto de energia é possível entregar à massa, desconsiderando as perdas por aquecimento, atrito, ruído e desgaste. Em outras palavras, quantos quilowatts consegue-se entregar para misturar 100 quilos de material.

Apenas como comparação, temos a seguinte tabela clássica:

Nenhuma entrada de índice de ilustrações foi encontrada.

$\mathrm{kW} / 100 \mathrm{~kg}$

Agitadores $<0,1$

Gravidade 0,1 a 1,0

Planetários

Horizontais de Pás $1-10$

Intensivos Horizontais $\quad 10-20$

Sigma 10 - 100

Intensivos Verticais 0,1 a 100

A ampla faixa de trabalho dos misturadores intensivos verticais, possibilitou sua utilização em diversas aplicações, ao entregar a energia exata necessária para cada processo, seja ela de mistura, aglomeração, plastificação ou dissolução dos materiais.

Para entender este conceito, podemos citar o exemplo da preparação de chantili, cuja receita básica é de leite e açúcar a serem batidos: caso a energia aplicada seja baixa demais, nunca se conseguira atingir a textura ótima, ficando apenas uma 
mistura de leite e açúcar. Caso a energia aplicada seja excessiva, a textura final obtida será de manteiga. Para preparar um bom chantili, a energia aplicada deverá ser especifica, a fim de se obter o resultado final esperado.

\section{3 - Mistura Intensiva para Granulação / Aglomeração de sínter}

\subsubsection{A priori:}

- Granulação: processo de obtenção de materiais esféricos, formato mais parecido possível a uma bola de futebol, e redondos, superfície mais lisa possível como uma bola de bilhar, com uma granulometria normalmente inferior a $5 \mathrm{~mm}$ (o que difere de uma pelotização).

- Aglomeração: processo de junção de vários materiais, com diversos formatos e características, onde o resultado final é uma granulometria superior a inicial, sem muita necessidade de se obter um material esférico e redondo.

Neste trabalho o foco maior será na aglomeração, porém, já foi verificado que a obtenção de materiais mais esféricos, redondos e com granulometria mais estreita, facilita a permeabilidade de gases em um forno para queima.

\subsubsection{Princípios:}

O processo de aglomeração de materiais parte dos seguintes princípios:

- Matéria-prima com uma granulometria inferior a desejada

- Necessidade de um aglomerante para gerar a interação entre os materiais (normalmente é utilizado um líquido)

- Necessidade de entregar a energia adequada para atingir o resultado pretendido.

\subsubsection{Fases}

Fases esperadas da aglomeração:

- Mistura: ao falarmos de formulação com vários componentes, espera-se que os materiais devam estar previamente homogeneizados, a fim de que cada aglomerado tenha a mesma formulação final.

- Adição de um meio líquido: o material mais usado como elo entre as partículas é água. A água irá gerar forças de van der Waals entre elas, a fim de que as partículas possam permanecer ligadas.

- Logo após a adição do líquido existe uma primeira fase de aglomeração, que chamamos de formação de núcleos, onde uma parcela dos materiais é aglomerada, formando as primeiras quase-partículas.

- A partir dessa fase, a energia aplicada gera forças capilares e a água tende a ir para a superfície do núcleo, possibilitando que partículas mais finas possam se aderir nele. Essa energia aplicada é de suma importância para a correta sequência do processo de aglomeração.

- Na medida em que continua o processo dentro do misturador, aumenta o tamanho dos aglomerados.

- Uma vez finalizados os finos no sistema (sendo eles aglomerados nas quasepartículas) podemos escolher algumas derivações para o restante do processo:

- Aplicar mais energia, com o objetivo de destruir as partículas, gerando novamente finos no sistema.

- Aplicar energia baixa: que possibilita a junção de duas quase-partículas, aumentando a granulometria final. 
- Aplicar energia média: possibilitando limitar a faixa granulométrica superior. É importante nesta etapa ter um tempo de processo ajustado e um aglomerante adequado afim de não danificar os aglomerados em fases subsequentes.

1.4 - Utilização da Mistura Intensiva para Sinterização

A utilização dos misturadores Intensivos Verticais está se tornando uma importante ferramenta, tanto em plantas existentes como em novos empreendimentos, devido a sua capacidade de processar uma crescente quantidade de finos nas formulações e regular a energia justa e necessária para uma correta aglomeração.

\section{MATERIAIS E MÉTODOS}

Nestes últimos 20 anos tem se desenvolvido diversas rotas para sínter utilizando os misturadores intensivos verticais:

1. Adicionando o misturador intensivo antes dos dois tambores

2. Substituindo o primeiro tambor por um misturador intensivo

3. Substituindo os dois tambores por dois misturadores intensivos, um deles com função de mistura e o outro de aglomeração

A rota mais comumente usada é a substituição do primeiro tambor, o mais comumente considerado tambor de mistura, por um misturador intensivo. A continuação, apresentaremos alguns resultados obtidos em processos deste tipo ao redor do mundo.

No esquema embaixo pode se ver o esquema do processo de sínter substituindo o primeiro tambor por um misturador intensivo. Deve ser considerada a adição de uma peneira antes da entrada do misturador para separar as partículas de maior tamanho que podem danificar o interior do equipamento.

\section{Processo sinterização com um misturador intensivo}

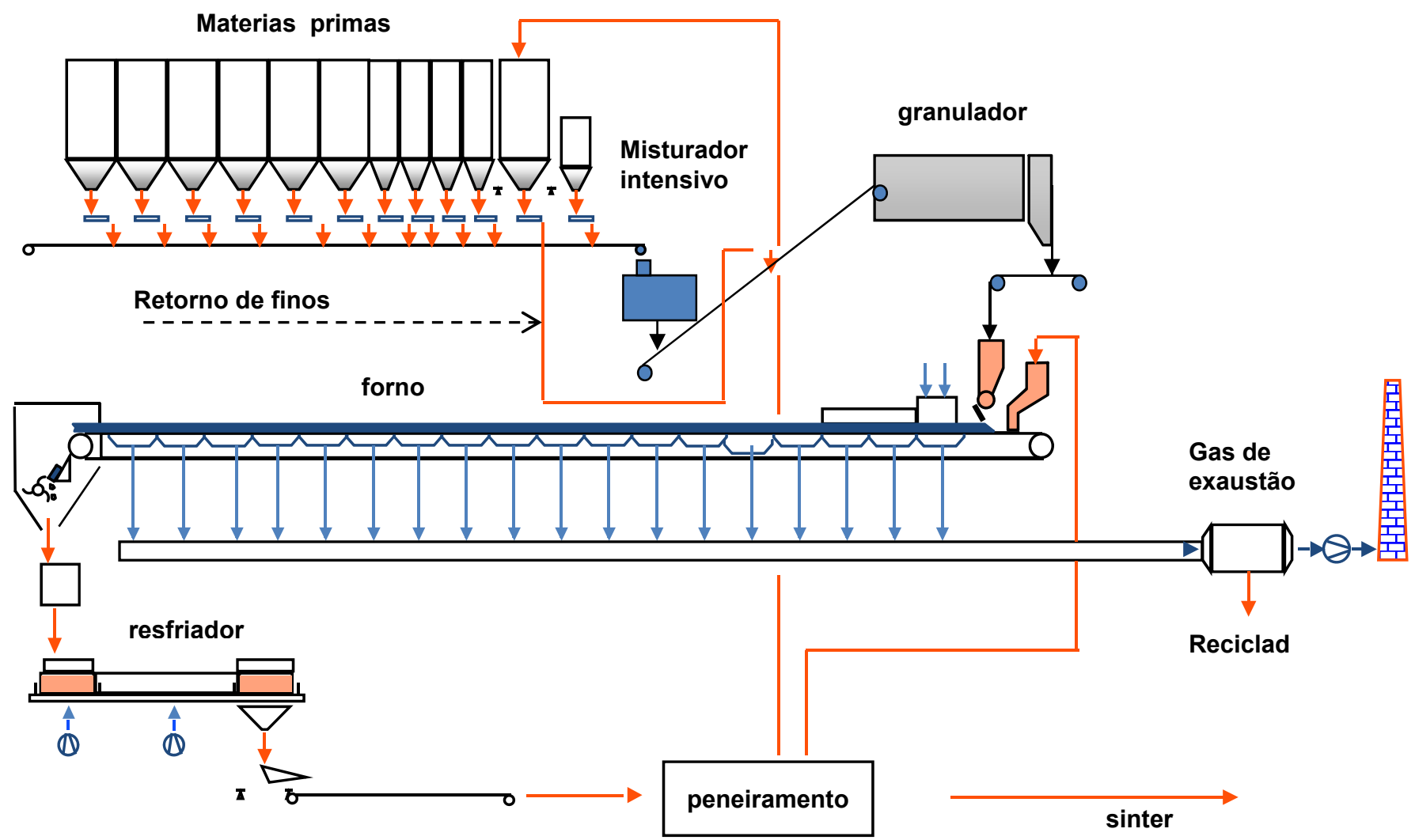




\section{RESULTADOS E DISCUSSÃO}

3.1 Redução de custos de operação da linha de sínter.

Como pode ser observado na tabela embaixo, a inclusão do misturador intensivo em Kokura 3 resultou na redução significativa de consumo de coque, energia elétrica, retorno de material e de sínter inferior a $5 \mathrm{~mm}$, enquanto aumentou a permeabilidade do forno, melhorando seu funcionamento.

\begin{tabular}{|l|c|c|c|}
\multicolumn{1}{|c|}{ Parâmetro } & \multicolumn{2}{|c|}{ Processo } & Com \\
& Tradicional & $\begin{array}{c}\text { Com } \\
\text { Misturador } \\
\text { intensivo }\end{array}$ & $\begin{array}{c}\text { Diferença } \\
\text { rendimento } \\
(\%)\end{array}$ \\
\hline Produção (t/dia) & 5.256 & 5.335 & $+1,50$ \\
\hline Consumo de coque (kg/t) & 40,5 & 39,3 & $-2,96$ \\
\hline Energia (kWh/t) & 16,5 & 15,8 & $-4,24$ \\
\hline Retorno do forno (\%) & 11 & 10 & $-9,09$ \\
\hline Sínter < 5mm. (\%) & 13,9 & 12,7 & $-8,63$ \\
\hline
\end{tabular}

\subsection{Aumento da permeabilidade no forno}

Além de reduzir variáveis de custo, a produção com o misturador intensivo em Kokura 3, resultou num notável incremento da permeabilidade do forno, como era esperado.

\begin{tabular}{|c|c|c|}
\hline Parâmetro & \multicolumn{2}{|c|}{ Processo } \\
\hline Permeabilidade (JPU) & 38 & $\begin{array}{c}\text { Com } \\
\text { Misturador } \\
\text { intensivo }\end{array}$ \\
\hline
\end{tabular}

\subsection{Aumento de produção}

$\mathrm{Na}$ tabela embaixo pode-se observar o aumento de produção do forno em comparação com a rota tradicional ao agregar o misturador intensivo e, ao mesmo tempo, aumentar a quantidade de finos na formulação do material. No caso em que o conteúdo de finos é baixo, não haverá diferença apreciável de produção, entretanto, a medida que a quantidade de finos incrementada em detrimento do minério, nota-se um aumento de produção de aproximadamente $20 \%$ com relação ao valor histórico de referência.

\begin{tabular}{|l|c|c|c|c|}
\multicolumn{1}{|c|}{ Parâmetro } & $\begin{array}{c}\text { Rota } \\
\text { Tradicional }\end{array}$ & \multicolumn{3}{|c|}{ Rota com 1 misturador intensivo + } \\
& 1,85 & 1,90 & 1,80 & 6,20 \\
\hline \% Pellet feed & 11,15 & 11,20 & 20,80 & 22,80 \\
\hline \% Concentrado & 547 & 547 & 654 & 641 \\
\hline Produtividade t/h & &
\end{tabular}




\subsection{Aumento da produtividade no forno}

Como resultado direto da incorporação do misturador intensivo ao processo, temos um ganho apreciável na produtividade do forno. Quanto mais finos sejam adicionados na fórmula, maior será a diferença de produtividade entre o processo tradicional e o baseado no misturador intensivo.

\begin{tabular}{|c|l|c|c|c|}
\hline & & \multicolumn{4}{|c}{ Formulação (\%minério + \%finos) } \\
\hline Parâmetro & \multicolumn{1}{|c|}{ Rota } & $17+4$ & $8+13$ & $0+20$ \\
\hline $\begin{array}{c}\text { Produtividade } \\
\left(\mathbf{t} / \mathrm{m}^{2} / \mathrm{dia}\right)\end{array}$ & Tradicional & 39 & 36 & 34 \\
\hline & C /Misturador intensivo & 45 & 42 & 41 \\
\hline
\end{tabular}

\section{CONCLUSÃO}

Ante a tendência irreversível de afinamento do minério nos próximos anos, seja pelo próprio sínter-feed ou pela necessidade de adicionar concentrado ou pellet feed, o misturador intensivo se apresenta como uma solução que permitirá manter ou até aumentar os níveis de produção e produtividade, mesmo com altos agregados de finos nas formulações. Ao mesmo tempo, dada a qualidade da mistura obtida, será reduzida a necessidade aglomerante e coque, comparado com os métodos tradicionais de sinterização, possibilitando a redução significativa de custos operacionais e melhorando o tempo de retorno do investimento.

\section{REFERÊNCIAS}

11995 Ironmaking Conference, Nashville, USA, 2-5 Abril. Yasuhiko Hadano et al.

2 Kokura Steel Works, Sumitomo Metal Industries Ltd, Japan

3 Improvement of granulaion on raw material by using the high-agitating mixer at Kokura No.3 sintering plant. 